\title{
NON-MOTORIZED MOBILITY IN THE CITIES OF THE 21ST CENTURY: AN EFFECTIVE START TOOL TO MITIGATE GLOBAL WARMING
}

\author{
Mohamed A. Zayed \\ Department of Architectural Engineering, Cairo University, Egypt
}

Nora M. Rehan

Department of Architectural Engineering, Modern Science and Arts University, Egypt

\begin{abstract}
Today, the Climate change becomes a global problem. Its harmful consequences threaten human life on earth. The latest researches agreed that Green House Gases are the key reasons of that dramatic change in the global climate. Motorized transportation means such as cars, trucks, ships and planes generate around $13.5 \%$ of these gases annually. As a result, and in a try to mitigate negative effects of climate change, many cities around the world addresses different approaches which are varied in their main framework, strategies and action. A special attention had been focused on the use of non-motorized transportation (walking and cycling) as a substitute to motorized means. Actually, many developed countries achieved clear progress in this issue. But unfortunately, less developed countries didn't. This paper addresses the importance of adapting bicycles as a main transportation mean in small sized cities. In addition, it will present a pilot project in Egypt to establish a non-motorized transport network in the city of Shebin-elkum, which is located in the western part of Nile delta. This paper depends on the experience of authors who are working in the project of sustainable transport in Egypt. It's a joint venture between Development Research and Technological Planning Center in Cairo University, the Global Environment Facility and the United Nations Development Program.
\end{abstract}

Keywords: Bicycles, motor-vehicles, cycling routes, urban upgrade.

\section{الملخص}

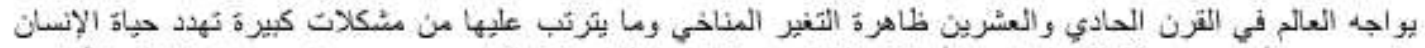

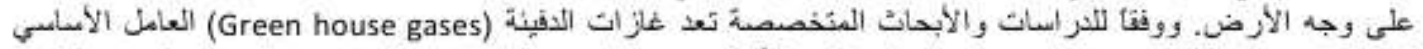

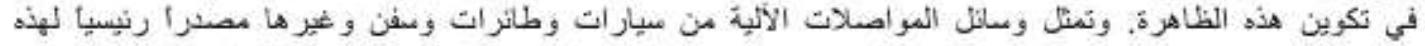

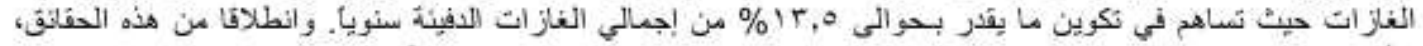

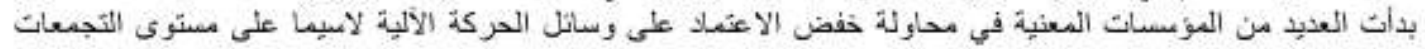

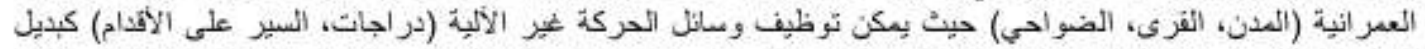

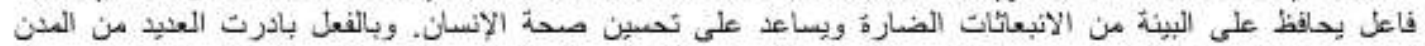

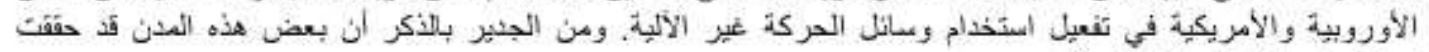

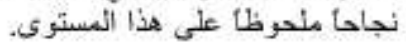

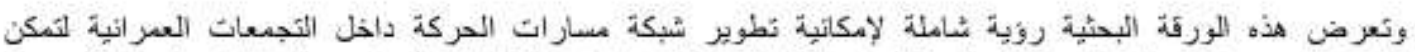

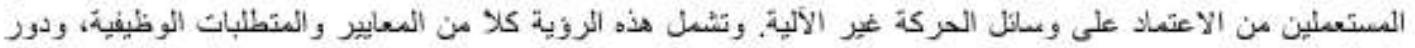

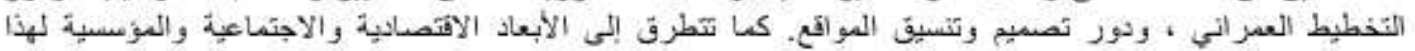

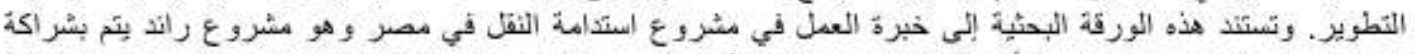

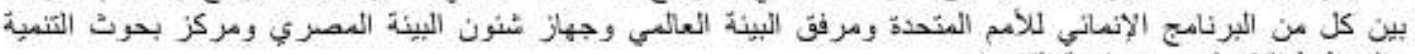
والتخطبط التكنولوجي بجامعة الفاهرة. 


\section{INTRODUCTION}

From the second half of the twentieth century, most of Egyptian cities are experiencing high population growth rates. This resulted in major challenges in these cities. One of these challenges is the extensive use of motorized transportation means especially cars and motorcycles. Unfortunately, the urban fabric of most of these cities weren't planned to accommodate these numbers of motor-vehicles. So, residents are suffering today from traffic congestions, higher air pollution rates and life quality deterioration. It's worth mentioning that this over-dependency on motorvehicles is a global act. Many other cities in the world, especially those in developing world, are also suffering from these problems. It's also important to address the climate change that threatens human life on earth. Recent studies concluded that motorized mobility on land that uses fossil fuel emits around $9.9 \%$ of the Green House Gases (GHG) which is the main cause of global warming ${ }^{1 .}$ This paper searches for solutions for the harmful effects of motor vehicles. It focuses on the ability of using non-motorized transportation in cities as a substitute of motorized ones. It discusses how to revive bicycling in order to reduce the use of cars and motorcycles.

\section{MOBILITY IN CITIES}

Patterns of human and goods mobility in a city are generated mainly from its urban planning. Both the urban area and the distribution of land-uses determine number of trips, length of each trip and mode of transportation. Cities with larger areas make its residents to travel longer distances. The world is witnessing a clear boom in the use of motorized transportation means, especially cars. In 2010, 646 million cars approximately are being used. In addition, the world will witness a growth in car ownership rate during the next forty years ${ }^{2}$ Today, many cities all over the world are congested with cars and other motorized transportation means. The situation in many of them is critical, as residents are suffering from many problems such as:

1. The increase of traffic congestions along day and night.

2. Lack of sufficient parking lots enforces drivers to park in wrong locations.

3. The increase in trip length, duration and fuel consumption per trip.

4. Continuous \& increased consumption of fossil fuel in private transportation. The amount fossil fuel consumed by transportation sector worldwide has been doubled from the 1970 to $2008^{3}$.

5. The rise of GHGs Emissions from cars for the same trip.

6. The negative effects on human physical and psychological health due to air pollution, noise and low physical exercise.

In response to this critical situation, two main approaches are addressed. These approaches are: 
1. Increasing the capacity of the roads network through establishing more bridges, tunnels and elevated roads, in addition to widen roads and adding more parking if there are vacant areas.

2. The development of transportation networks and introducing more efficient systems, in addition to enhance integration between land-uses and transport.

The first approach is the traditional one that most cities around the world adopted starting from the seventies of the twentieth century. It encompasses short-term actions that can relieve traffic congestions. But, it will also encourage more and more car usage, which will cause the same problems (congestion and pollution) again but on larger scale ${ }^{4}$.

The second approach, despite being a long-term one, introduces a real solution for the critical dominance of harmful motorized mobility. This approach not only focuses on introducing more efficient transport means, but also highlights the correlation between land-uses and urban form and mobility demand. This multi-dimensional approach targets to achieve acceptable balance between citizens comfort, environment sustainability and community development. It covers three main areas of research, which are detailed as follows.

\subsection{Introducing alternative modes of private transport}

Motorized private vehicles such as cars and motorcycles are responsible of major problems of harmful emissions and congestions. Scientific calculations concluded

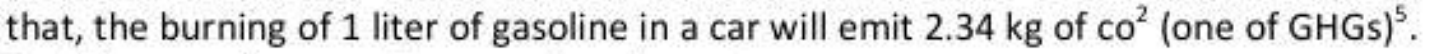
So, this area of research has a unique importance.

Alternative modes can be classified into two main groups. The first one is the nonmotorized means such as bicycles, scooters and walking. Urban planners have a key role to upgrade the urban fabric of cities to encourage residents to use these means. The second group includes clean motorized means that have zero emissions such as electric cars and solar cars. It's worth to mention that, these new vehicles are still under research and development to be widely marketed. Figure (1) presents samples of these vehicles.

Figure (1) Samples of clean motor vehicles (solar car \& electric car)

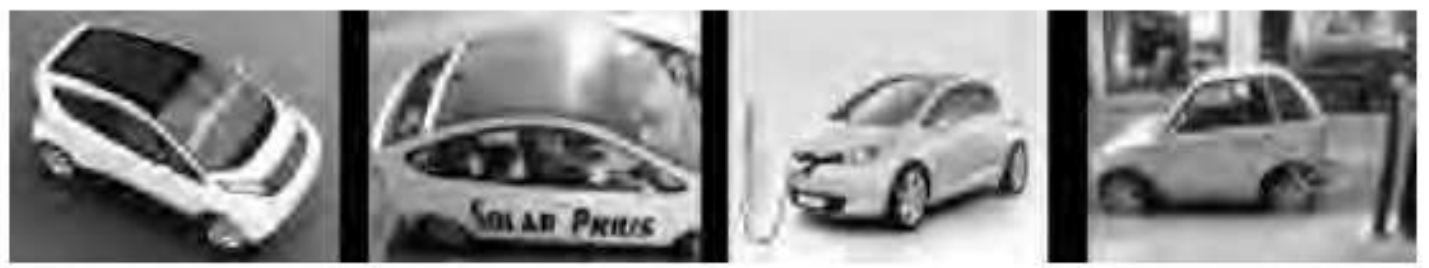




\subsection{Developing public transport means (metro, train, light rail, bus, etc.)}

Well planned public transit offer real opportunities to leave private cars. Use public transportation means help in both reducing $\mathrm{co}^{2}$ emissions and traffic congestions. In 2005 , public transit in US succeeded to reduce $\mathrm{co}^{2}$ emissions by 6.9 million metric ton, as estimations predicted that every passenger use public transit instead of private cars will save 2.2 metric tons approximately ${ }^{6}$. In 2002, the electric light rail transit in Calgary city, Canada, reduced around 20000 ton of GHGs and other pollutants ${ }^{7}$. Public transit needs accurate planning and integration with land uses and housing areas. In addition, public transit saves large areas that were to be filled with private cars. Figure (2) illustrates the area required for the mobility of 50000 passengers per one hour for one direction for different modes of transport in city ${ }^{8}$.

Figure (2) Area required for the mobility of 50'000 passengers for 1 hour/direction.

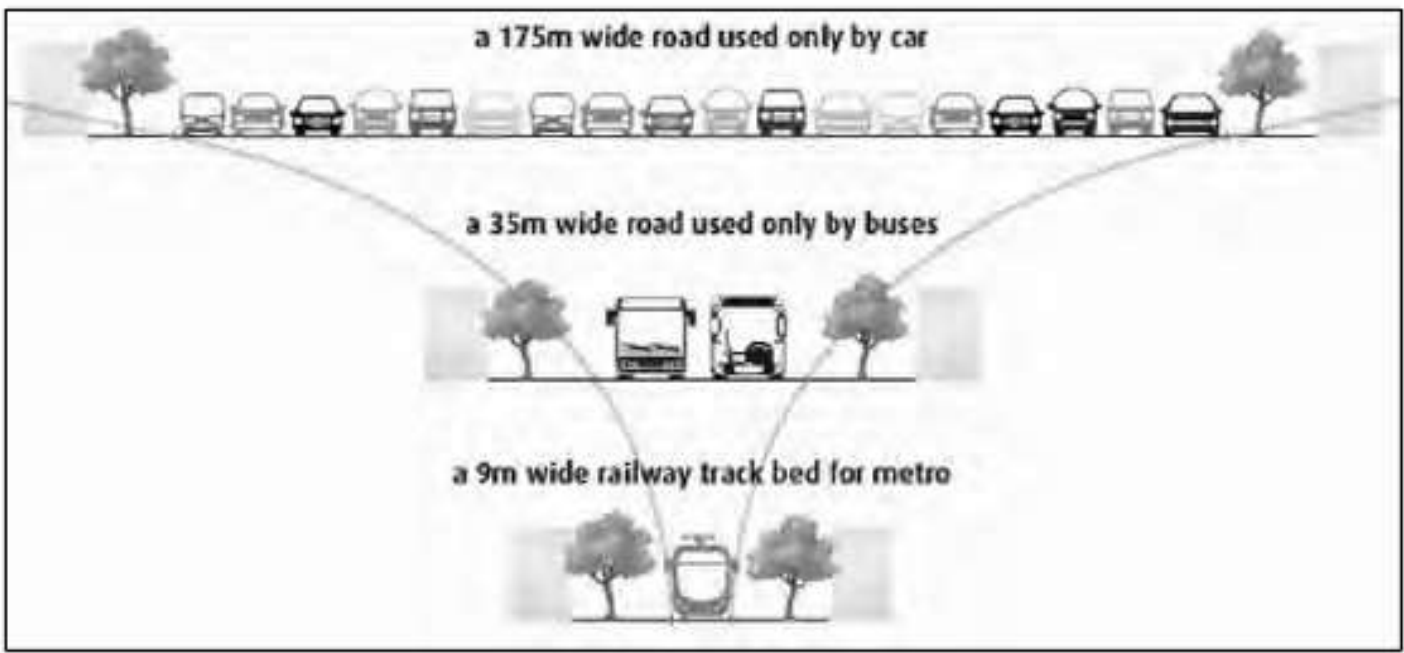

\subsection{Redistributing and adjusting land-uses to minimize mobility distances}

Urban development pattern plays an essential role in creating mobility demand in the city. There are many urban policies that can help mitigating harmful effects of motorized transport. The main three policies are mixed-use development, densification and land-value taxation. These policies are mid-term and long-term ones. Their effects will be maximized when integrating with public transit systems.

Adopting the second approach will help not only in relieving traffic congestions but also in mitigating air pollutions and of course global warming. Table (1) presents a comparison between the three areas of research. It's clear that this approach is a comprehensive and flexible one that is suitable for different circumstances and characteristics of cities. Single action or a combination of more than one could be organized in one integrated program that will help in overcoming the problems of motor vehicles overusing. The remaining part of this paper will focus on the nonmotorized transport system as one of effective tools. 
Table (1) Comparison between the three dimensions of the integrated approach

\begin{tabular}{lccc}
\hline Criteria & $\begin{array}{c}\text { Alternative modes of } \\
\text { private transport. }\end{array}$ & $\begin{array}{c}\text { Developing public } \\
\text { transport }\end{array}$ & Adjusting land-uses \\
\hline Framework & Alternatives supply & Alternatives supply & Demand minimizing \\
\hline Range & Short term action & Short term action & long term action \\
\hline Effect & Direct effect & Direct effect & Indirect effect \\
\hline Urban area size & Small & Medium/large & Medium/large \\
\hline Depends on & $\begin{array}{l}\text { Individual willingness, } \\
\text { skills and affordability. }\end{array}$ & $\begin{array}{c}\text { Integration with other } \\
\text { transport means \& with } \\
\text { land-uses. }\end{array}$ & $\begin{array}{c}\text { Urban planning vision } \\
\text { and processes. }\end{array}$ \\
\hline Requirements & $\begin{array}{c}\text { Special routes, parking } \\
\text { facilities. }\end{array}$ & $\begin{array}{c}\text { Extensive infrastructure } \\
\text { (e.g., routes, garages, } \\
\text { terminals) }\end{array}$ & $\begin{array}{c}\text { Strong legislative } \\
\text { framework. }\end{array}$ \\
\hline
\end{tabular}

\section{NON-MOTORIZED TRANSPORTATION}

Before the invention of motor-vehicles, urban mobility was depending on walking, bicycling and riding animals and animal-drawn carts. These means were characterized by low speed, limited dangerous accidents and environment friendly. Some of these means are now obsolete and disappeared from some cities. Actually, Bicycle is one of non-motorized means that still has an existence in the $21^{\text {st }}$ century.

\subsection{Bicycling}

Bicycle is one of the oldest transportation means that human used. Compared with other non-motorized transportation means, bicycles are faster than walking or riding some kinds of animals. It doesn't require special care or feeding like animals. After the emergence of motor-vehicles, the use of bicycles declined steadily. That's because they are faster and don't require human power as they depend on fossil fuel instead.

\subsection{The potentials of bicycling in urban areas}

Considering the current situation of cities, bicycles have strategic potentials as a helpful transportation mean. These potentials are:

1. Providing the possibility of faster moving in congested streets that suffer from traffic jams. This is resulted in saving time, effort and physical and psychological fatigue.

2. Relatively low cost mean for transportation.

3. As it totally works on human muscles, it gives bicyclist a good opportunity to exercise some physical activity that is required and necessary to maintain health. It should be noted that the life style in the $20^{\text {th }}$ century no longer provides an opportunity for physical exercise.

4. Bicycles physical requirements are limited. 
5. Using bicycles doesn't require burning fossil fuels, so there are no harmful emissions from it.

6. In small sized cities, establishing most of public transport systems is unfeasible due to the limited number of passenger. So bicycling is more suitable.

\section{BICYCLE NETWORK IN CITIES}

In order to encourage people to use bicycles, it's important to establish cycling network that guarantee appropriate and safe areas to move and park. To establish such a network, of course, streets and roadways are the best nominated areas in the city urban fabric. Three important issues should be addressed. These issues are the plan of routes, the design of bicycling paths and the design of bicycles parking. Following is a brief description of each element. Data is collected from best practices of bicycles transport initiatives in some of developed world cities.

\subsection{The plan of bicycling routes}

It encompasses the selection of certain routes to be developed for bicycling. The urban planning of city will greatly affect that selection. Land-uses and urban area are the main factors. Land-uses that have public activities such as schools, colleges, shopping malls, parks and governmental agencies usually have large numbers of users who can use bicycles. So, streets that linked between such land-uses are nominated for bicycling network. In addition, terminals and stations of public transport are also important destinations for bicyclists.

From analyzing the bicycling maps of some cities, it's found that, bicycling routes may be either connected in one network or scattered into isolated routes. In addition, the area of city which determines the distance between homes and destinations plays an essential role on the propensity to commute by bicycle. Five to eight kilometers is the optimum range for cycling. ${ }^{910} 11$.

\subsection{The design of bicycling paths}

Pioneer cities in establishing bicycling routes network use one or more of the following types: ${ }^{1213}$

\subsubsection{Isolated paths}

It's totally isolated from the roadway. It has many other names such as bicycle path, cycle track and off-road path. It is a paved path that is separated by landscape elements from the street. Its level is different from the street level. Only bicycles are allowed to move in it and sometimes pedestrian. ${ }^{14}$ The acceptable width for this type ranges between 2.0 to 4.0 meters. Sometimes, another form of this path could be offered by deducting part of the street by concrete or metal boarder which prevents all other transportation means to get in this path. In this case the bicycling path will be at the same level of the street. Figure (3) illustrates the two forms of this type. 
Figure (3) Examples for the isolated bicycle path (left), Examples for deducted bicycles paths (right)

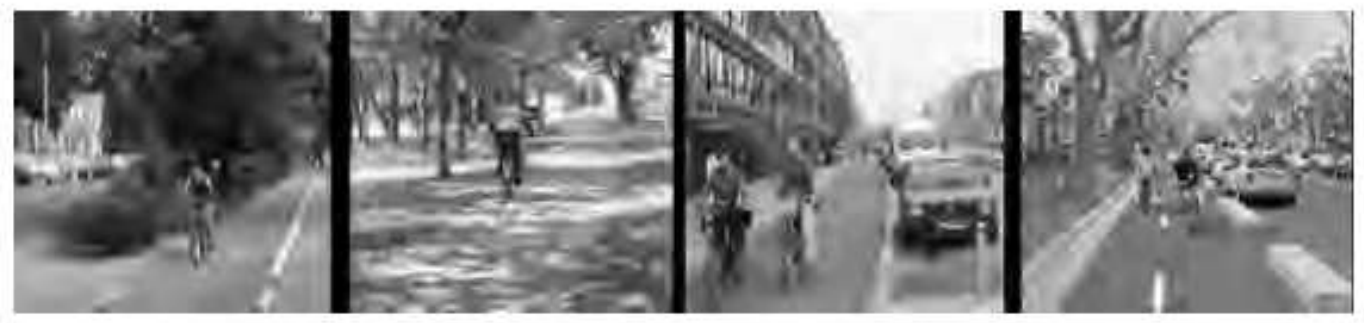

\subsubsection{Exclusive bicycles lanes}

It's also known as Cycle lanes. In this type, a part of the street is dedicated for bicycling. This part is determined by using distinctive colored marking only ${ }^{15}{ }^{16}$, no physical barriers like the previous type. The acceptable width for this type ranges between 1.2 to 3.0 meters and it should be free from any obstacles such as rain drain units or manholes. ${ }^{17}$ Sometimes like rush hours or emergencies, local authorities permit cars to move in these paths. ${ }^{18}$ Figure (4) presents examples for this type of paths.

Figure (4) Examples for exclusive bicycles lanes

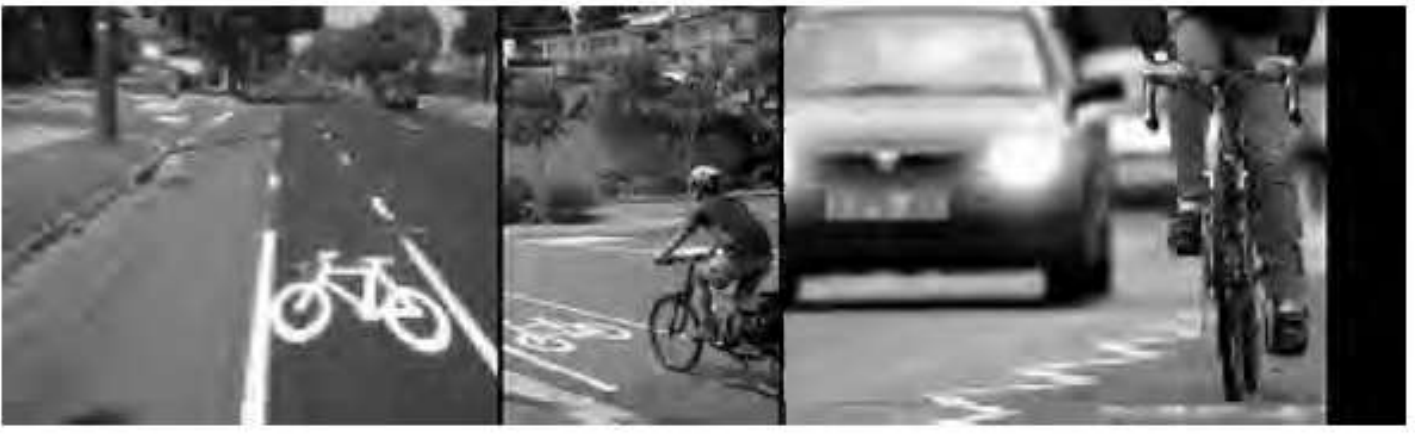

\subsubsection{Combined routes}

It's known as Wide Kerbside Lanes or Bicycles routes. In this type, a part of the street is dedicated for the motion of both cars and bicycles. Only some traffic signs will be used to indicate that this part of the street for the both types of transportation. It's suitable for narrow streets where it's impossible to deduct part of its width for bicycling. The acceptable range for this combined routes ranges from 3.7 to 5.0 meters. Figure (5) presents examples for this type.
Figure (1) Examples of combined routes

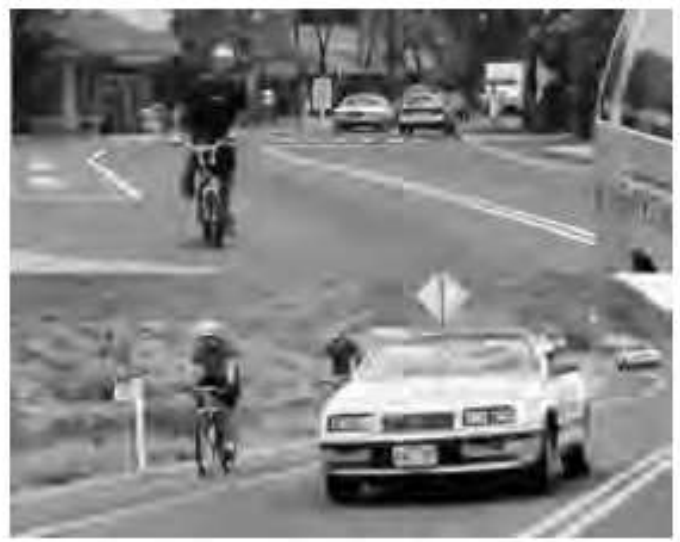


A previous study ${ }^{19}$ concluded that bicyclists prefer the isolated paths because it's safer than other types. On the other hand the cost of establishing this type is relatively high. Another study ${ }^{20}$ indicated that bicyclists are ready to pay extra fees to develop exclusive bicycle lanes as its construction cost is less than isolated paths and meanwhile offers a moderate grade of safety.

\subsection{The design of bicycles parking}

Offering adequate and enough bicycles parking is very important in establishing bicycling network. Monitoring reports for existing bicycles network assured that, the emergence of parking areas for bicycles is one of the important factors for encouraging people to use bicycles instead of cars. In addition the absence of parking facilities will enforce bicyclists to park their bicycles in wrong areas ${ }^{21}$. This will resulted in harmful effects on streetscape and pedestrians. When designing bicycles parking, the following issues should be considered 222324 :

1. Parking areas should be close to user destination.

2. Parking areas should be easily accessed from surrounding routes.

3. Parking areas should be overlooked by public, staff or security cameras.

4. Access to parking should avoid any conflict with pedestrian movement.

5. Parking facilities shouldn't create a hindrance to other users.

In addition, it's important to provide enough number of bicycles parking areas. There are three main types of bicycle parking facilities that are most popular all over the world. These types are 252627 :

\subsubsection{Bicycle Locker}

It's a fully enclosed space that is dedicated to store one bicycle only in each one. It's more suitable for long term parking that lasting for hours. It offers the maximum physical security for bicycles especially from weather, vandalism and theft ${ }^{28}$. Its design allow bicyclist to store other personal accessories such as helmet, panniers and clothing ${ }^{29}$. It's locked by key, code number or swipe card. Bicycles may be stored in either horizontal or vertical position according to locker design. This type requires larger areas compared to other types of bicycles parking. Figure (6) presents examples for this type.

\subsubsection{Bicycle Enclosure.}

A long term parking facility that offers a closed compartment that has a group of bicycles rails. This cage should have a solid roof to offer a shelter from weather. Cage walls are constructed from a chain-mesh or other see-through material to allow natural surveillance. An employer is responsible for the security of the cage and bicyclist is responsible of securing his bicycle to rail. This type of parking is usually suitable for land uses that have big number of bicyclists. Figure (7) presents some examples of bicycles enclosure. 


\subsubsection{Bicycle Rails}

This type is most popular and economical bicycle parking facility. It's just a metal rail that is strongly fixed to earth. Rails are produced in a wide range of forms and colors. This type is used for short term parking. It doesn't require large area like the previous two types. On the other hand, it offers the minimum physical security. Figure (8) presents some examples for bicycles rails.

Figure (6) Examples of bicycles lockers
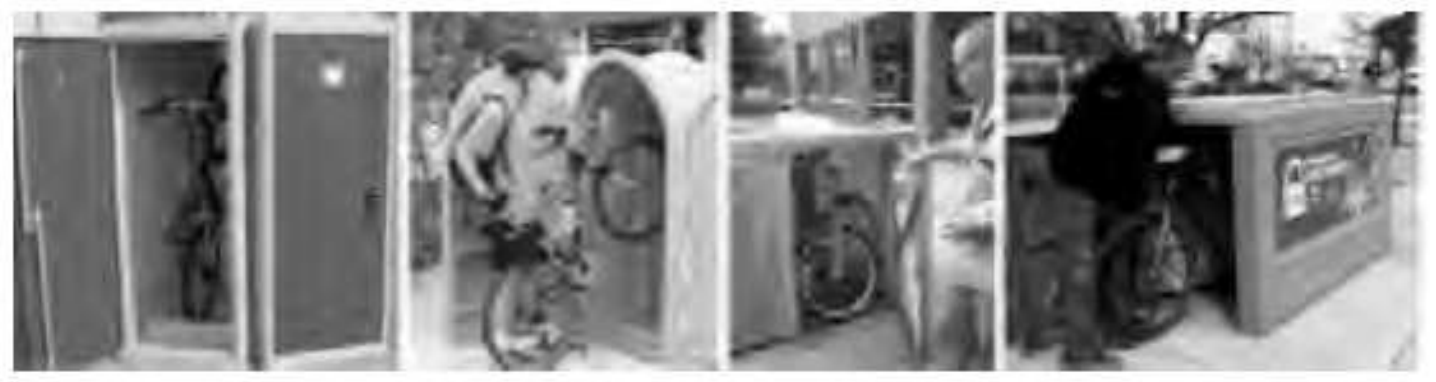

Figure (7) Examples of bicycle enclosures
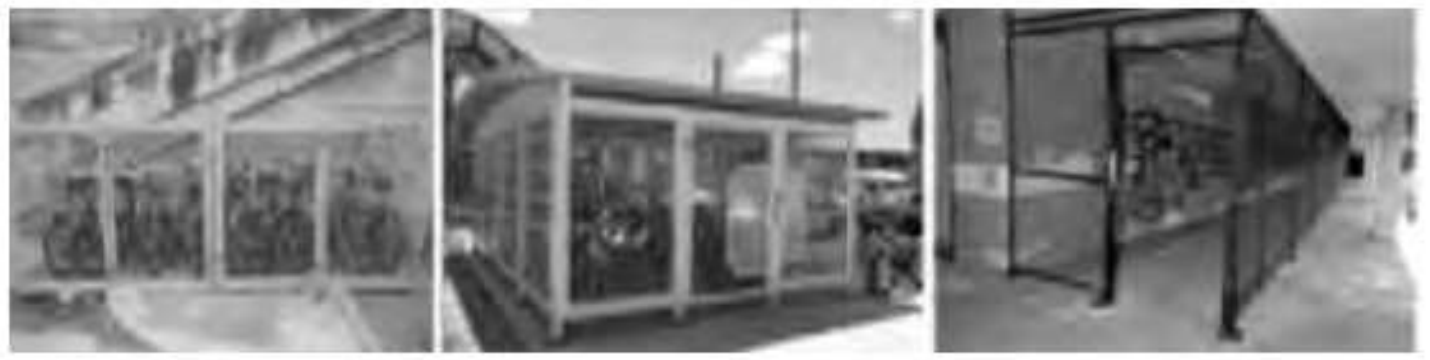

Figure (2) Examples of bicycles rails
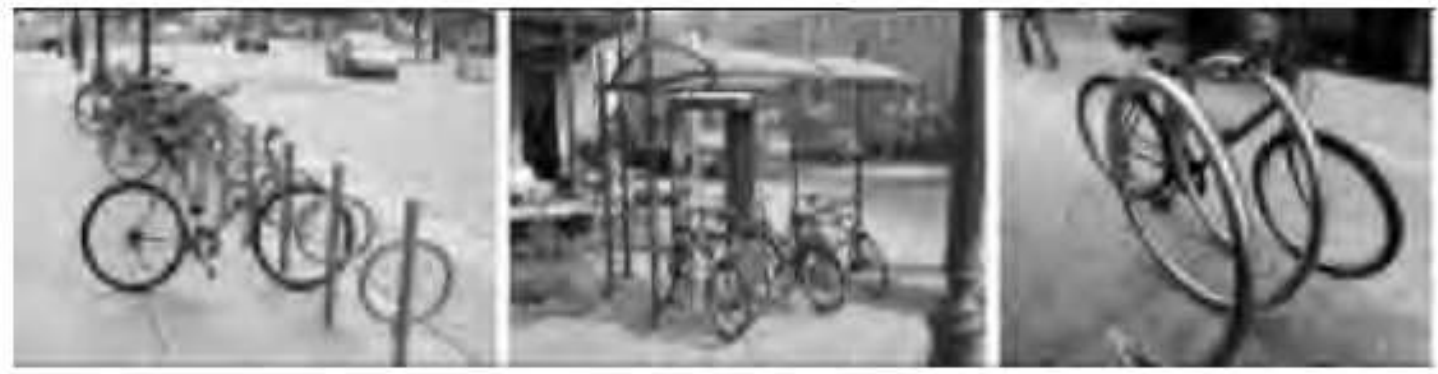

\section{AMSTERDAM: A PIONEER CYCLING CITY}

Amsterdam is the capital of Netherlands. Its population reaches 770,000 inhabitants approximately ${ }^{30}$. The city of Amsterdam is synonymous with cycling. From decades, the bicycles policies have the priority. All parties focus on how to utilize bicycles more and more in everyday life in the city. Actually, the city of Amsterdam has one of largest cycling networks in the world. Appendix (1) introduces more facts and details about the cycling network in the city. 


\subsection{Strategies and policies}

Starting from early 1970s, the city of Amsterdam addressed the dangerous threats of solely depending on motor vehicles. So, it adopted a tow dimensional approach to overcome this threat. The first dimension is to restrict car use and the second one is to promote alternative modes of transport that are user-friendly, economic and socially equitable ${ }^{31}$. Following is a brief description for the policies and actions that come under each dimension. To restrict car use, the city takes the following actions:

- Increase taxes for both gas and automobiles sales ${ }^{32}$.

- Reduce car parking areas in city center and increase the fees of the remaining ${ }^{33}$.

- Calming traffic speed down to $30 \mathrm{~km} / \mathrm{h}$. in many residential areas ${ }^{34}$.

- Convert streets to one way for cars and others reserved for non-motorized transport ${ }^{35}$.

On the other hand, to promote alternative modes of transport, the city takes the following actions:

- Creating safe, user-friendly and better cycling facilities ${ }^{36}$.

- Establish Park \& Bike facilities that enable residents to park their cars and use bicycles instead for short travels in the city $^{37}$.

- Bicycle training sessions for children in their schools ${ }^{38}$. Figure (9) presents photos for Figure (9) Training children to bicycles one of these sessions.

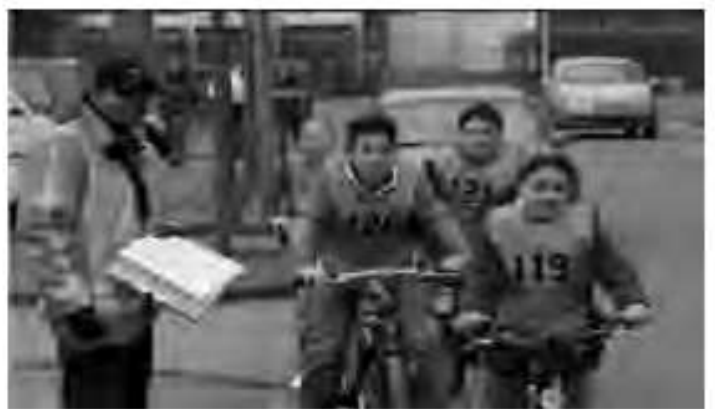

- Coordinate cycling routes and facilities with other public transport modes such as train $^{39}$.

- Encourage employees to cycle to their work through awarding them by free shopping and outings ${ }^{40}$.

- Apply traffic rules that force car drivers to take care for cyclist life. And in most cases put the responsibility for an accident on the car driver ${ }^{41}$.

- Undertake various promotional measures to enhance interest to cycling ${ }^{42}$.

\subsection{Current status of Amsterdam city}

Today, Amsterdam is one of the sustainable cities of the world. In 2010, it was nominated to be the green capital of Europe. The city succeeded to considerably reduce the air pollution rates ${ }^{43}$. This is a result of the adopting of cycling as a part of integrated approach that combines other strategies such as public transport, electric cars, urban mobility and a special focus on bicycles. In 2011, the city ranked second in the transport index and ranked fifth in the Green city index ${ }^{44}$. In addition, notable increase in life expectancy is achieved recently ${ }^{45}{ }^{46}$. Finally, Amsterdam city provides 
an excellent example of how a city can turned to be more sustainable and livable through utilizing alternative modes of transport especially bicycling ${ }^{47}$.

\section{THE POSSIBILITIES OF ESTABLISHING BICYCLES NETWORK IN EGYPTIAN CITIES}

In the last decade, the majority of Egyptian cities are suffering from traffic jams, high air pollution rates that resulted from the over dependence on motor vehicles. As a result more money, time and effort are consumed in urban mobility. The multidimension approach that is previously discussed in this paper is recommended as a solution for these problems. For small sized cities, introducing non-motorized transport means may be the short term action that could be started with. After that, the remaining medium and long-term actions should be addressed. Generally speaking, non-motorized transport means is suitable for many of Egyptian cities for the following reasons:

1. Urban area of the city is small, so the average distance between land-uses will be within the range of 8 kilometers. This rule will be applicable for compact shape (not linear) cities with area don't exceed $50 \mathrm{~km}^{2}$.

2. Pollution rates are less than large cities, so side effects on bicyclist health will be at minimum in these cities.

3. In the absence of adequate public transportation system, bicycles will be the most suitable choice for middle and lower income people.

4. Egypt is characterized by moderate climate, so bicycles users won't face the problems of cold, rains, and storms.

5. Most of Egyptian cities have no steep topography. It means that no extra physical power is required for bicycling in these cities.

\section{CYCLING IN SHEBIN-ELKOUM CITY: A PIONEER INITIATIVE IN EGYPT}

A pioneer initiative was started at 2005 by the Development Research and Technological Planning Center (DRTPC) in Cairo University in company with both Egyptian Environmental Affairs Agency (EEAA) and the Global Environment Facility (GEF). This initiative is known as The Sustainable Transport project in Egypt. It's a multi-components project that aims to create efficient means as substitutes to motorized transportation in order to mitigate some environmental problems. One of its components is the non-motorized transportation program. This program targets to establish bicycles networks in some Egyptian cities. One of these cities is the city of Shebin-Elkoum.

\subsection{Current status of Shebin-Elkoum}

Shebin-Elkoum city is the capital of Munufeia governorate. It is located 60 kilometers to the northwest of Greater Cairo. In 2006, the city population was 177,112 inhabitants. The approximate urban area is $10 \mathrm{sq}$. kilometers. The city depends on three main economic activities. These activities are textile industry, agriculture and regional services. The city had a long heritage of using bicycles. For the last 4 decades of the last century major part of population was using bicycles. But from 
2000, motorcycles took its place. Figure (10) presents a map and an aerial view for the city.

Figure (10) Map of Shebin-Elkoum location from Greater Cairo (Left), Aerial view of Shebin-Elkoum city (Right)
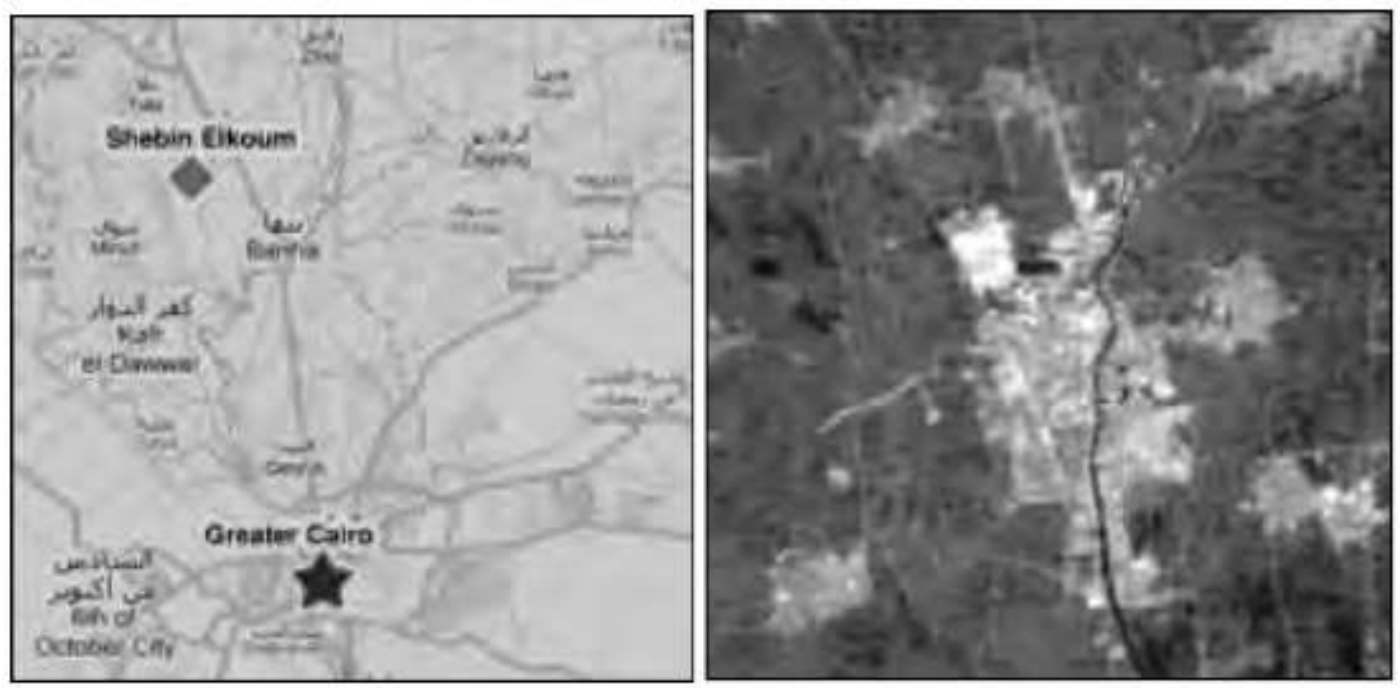

\subsection{Main framework}

The program of adopting bicycles as a mode of transportation in the city includes three main modules. The first one is the establishment of cycling routes network. It's the main action in this program. It aims to create safe routes network for cycling. The second one is the urban upgrade of some parts in the city. Actually, this module has direct and indirect objectives. The direct one is to rehabilitate pavements in the proposed cycling network in order to fit to pedestrian mobility. The indirect objective is to create a positive response from the local community to the cycling network, as they will feel some type of correlation between establishing of such a network and urban upgrades of their home city. The third one is the supportive actions. It will introduce the essential economic and social support through community awareness program and bicycles services (buying, renting, repairing facilities).

\subsection{Proposed plan of cycling routes}

Through urban and traffic analysis of the current status of the city accompanied with workshops with local authorities and governmental agencies, a group of 7 routes has been chosen. Some of these routes are full streets and others are parts of streets. The total routes length is 8 kilometers. Appendix 2 introduces the details of the cycling network in the city. These routes have been chosen according to the following criteria:

1. Routes should be established in relatively wide streets. It will fit to dedicate certain parts of them for cycling.

2. Important land-uses and activities are existed on the sides of these routes such as markets, schools, stadium, university, governmental agencies, 
recreational facilities and textile factory. Figure (11) illustrates these landuses.

3. The selected streets located in the core of the city, so major part of daily trips will move though this network. Figure (3) illustrates the location of the cycling network in the city urban fabric.

Figure (11) Distribution of land-uses along the proposed network

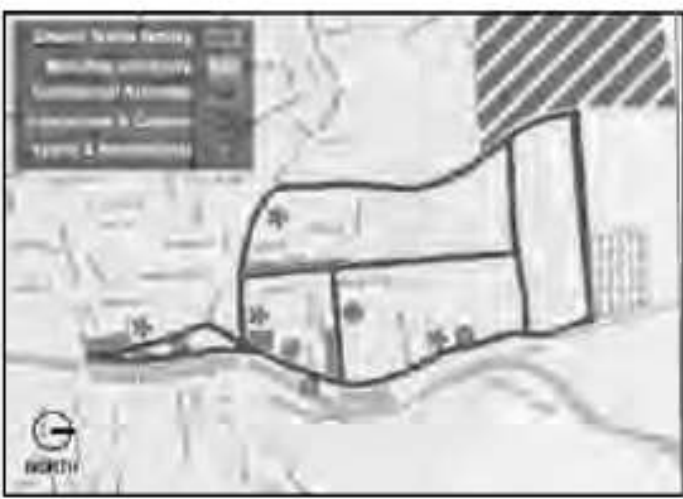

Figure (3) Location of cycling network in Shebin Elkoum city

\subsection{Routes Design}

The relationship between vehicles mobility and bicycles should be addressed carefully. Two main principles should be adopted. The first one is the safety of different types of street users and the second one is vehicles flow maintaining. So, clear separators are used to distinguish as possible the routes for each type of transport. Figure (4) illustrates the relationship between the mobility of vehicles and bicycles through using different types of separators.

Figure (4) Proposal of deducted bicycle paths in wide streets (Left) Proposal of combined routes in narrow streets (Right)
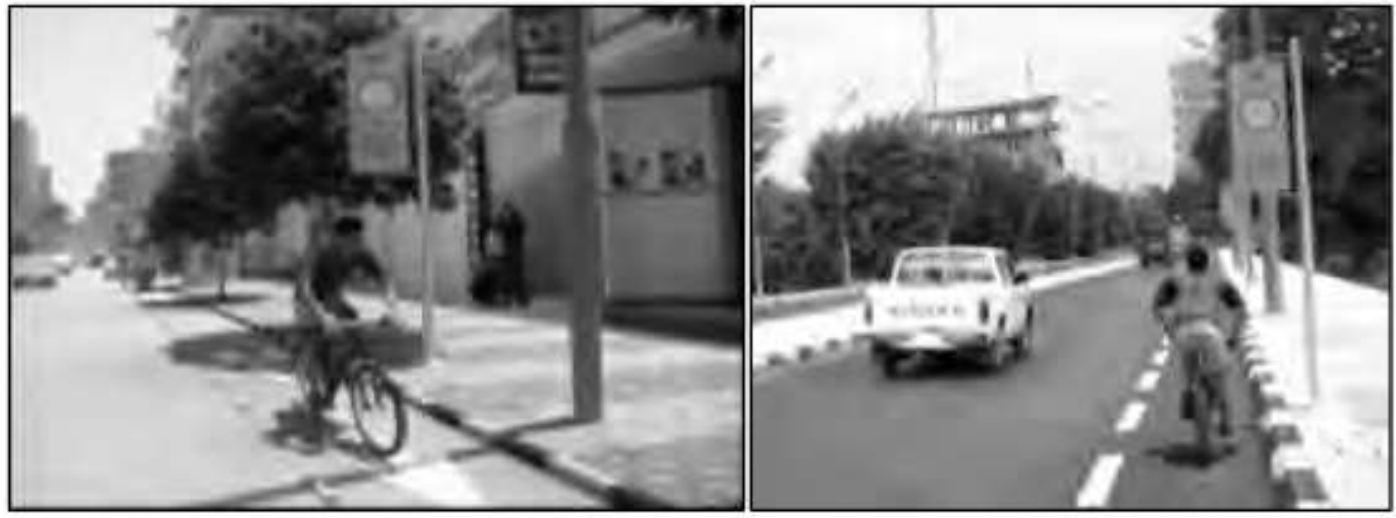

\subsection{Challenges}

The main challenge is the local traffic department objection on taking parts from streets and converting it into isolated cycling tracks. Their point of view is that such 
action will result in reducing streets capacity which will lead to more traffic congestion and increase rush hours. In addition, another objection on changing traffic plans in the city to adapt to the new transportation mean. Of course all these objections are based on lack of experience concerning the cycling in the city. Such challenges may be overcome by the following:

1. In relatively narrow streets, adopting combined routes instead of exclusive bicycles lanes. This will enable car drivers to use the full width of the street in rush hours.

2. Wherever possible, some modifications could be done for the pavements. So some parts could be changed to exclusive bicycles lanes to keep streets with its original width. It's very important to consider any side effects that could happen to pedestrian. Urban upgrade will determine how this will be done.

3. Make effects assessment study that will help to predict the future traffic pattern and cars usage after the execution of the project. As cities that adopt cycling witnessed a notable decrease in cars usage. In such case, taking parts from the street width will have no negative effects.

\subsection{SWOT assessment}

Table (2) introduces the final assessment of the non-motorized transport project in the city of Shebin El-koum using SWOT analysis method.

Table (2) SWOT assessment for Sebin El-koum non-motorized transport project.

\begin{tabular}{ll}
\hline \multicolumn{1}{c}{ Strengths } & \multicolumn{1}{c}{ Weaknesses } \\
\hline $\begin{array}{l}\text { - Long heritage of bicycling. } \\
\text { - Small urban area, so most of travel } \\
\text { distances are within } 5-8 \mathrm{~km} .\end{array}$ & $\begin{array}{l}\text { Relatively narrow streets. } \\
\text { Growing trend towards fossil-fuel } \\
\text { burning four-wheeled and three- } \\
\text { wheeled vehicles. }\end{array}$ \\
$\begin{array}{l}\text { - } \text { - Low running cost for bicycles. } \\
\text { - Relatively low cost for non-motorized } \\
\text { facilities establishment. }\end{array}$ & $\begin{array}{l}\text { - Suggested network passing by most of } \\
\text { important land uses in the city. }\end{array}$ \\
$\begin{array}{l}\text { - Strong financial \& technical support } \\
\text { from national \& local authorities. }\end{array}$ & - $\begin{array}{l}\text { Strong competition from low quality } \\
\text { and cheap motorcycles. } \\
\text { - Ability of applying new technologies } \\
\text { such as e-bikes in the future. }\end{array}$ \\
\hline
\end{tabular}

\section{Evaluating Amsterdam and Shebin El-koum cycling programs}

Amsterdam cycling program is a mature initiative that succeeded to reinvent riding bicycles as a mode of life. It adopted a multi-dimensional approach that based on both restricting motor-vehicles use and promoting cycling as a substitute. The initiative offers huge investments and permanent support staff who work to make 
cycling easier and safer. After forty years, the city has homogenous transport network that combines different modes of both motorized and non-motorized mobility. On the other hand, Shebin El-koum program depends on one-dimension approach that promotes the cycling by creating suitable paths, adequate parking facilities and society awareness activities. It's worth mentioning that it's the first time in Egypt that such a program introduced. So, it is still pre-matured and needs many more developments that widen the scope of works to include more dimensions, especially those of reducing the over-dependence on motor-vehicles.

\section{Conclusion}

Multi-dimensions approach is recommended for applying in cities to mitigate the harmful effects of motor vehicles over-dependency. This approach has diversified strategies that make it suitable for almost all different social, economic and urban circumstances of cities. For small sized cities, introducing non-motorized transport means could be that start, as cycling offers a great opportunity for urban mobility. It's a strategic mode of transportation for short distances that range between 3 to 8 kilometers. Many critical negative effects of motor-vehicles overusing may be mitigated by adopting this new mode of transportation. Small sized cities in Egypt have the potential to adopt bicycles as a substitute to motor-vehicles. The flat topography, the moderate weather and the small urban area of these cities are all factors that enable the comfort use of bicycles. Although the physical requirement for urban cycling is relatively limited, it's very important to introduce a comprehensive plan to encourage local community to use bicycles. That is because competition from motor-vehicles is strong as they appear as an easier tool for transportation that doesn't require human power to move. Offering adequate parking facilities, giving priority for cycling traffic and societal awareness programs are as important as creating safe cycling routes network. Converting urban mobility in Egyptian cities from motor-vehicles to bicycles may be a hard mission in the start but once done, it will help these cities to solve many environmental and health problems.

\section{APPENDIX 1: Facts about Amsterdam cycling network}

\section{A.1. Important facts about cycling in Amsterdam:}

- In 2006, the city has $600^{\prime} 000$ bicycles $^{48}$.

- In 2008 , approximately $75 \%$ of city residents own bicycles. And half of them use bicycles every day ${ }^{49}$.

- In $2008,37 \%$ of all movements done in the city use bicycles vs. $41 \%$ uses cars and $22 \%$ use public transport ${ }^{50}$.

- In 2009, a team of 60 employees in the department of traffic and transport infrastructure is responsible to promote bicycling in the city ${ }^{51}$.

- For the period 2006-2010, the city allocated 100'000'000 euros for bicycling in the city ${ }^{52}$. 


\section{A.2. Cycling network planning}

The city of Amsterdam has one of largest cycling networks in the world. It's a unique network of bicycle-friendly routes that cover almost all parts of the city ${ }^{53}$. In 2007, this network had a total length of $450 \mathrm{~km}$. it consists of three types of cycling routes. The first type is isolated paths with total length of $200 \mathrm{~km}$. the second type is combined routes (along streets with $30 \mathrm{~km} / \mathrm{h}$ traffic) with total length of $200 \mathrm{~km}$. the third type is exclusive bike lane (along streets with $50 \mathrm{~km} / \mathrm{h}$ traffic) with total length of $50 \mathrm{~km}$. In addition, $900 \mathrm{~km}$ of roads in the city (around $60 \%$ of the total roads network) is cycling friendly by calming traffic speed to $30 \mathrm{~km} / \mathrm{h}$ only ${ }^{54}$. Figure (14) illustrates this network ${ }^{55}$, and Figures (15) and (16) presents photos for bicycles route.

Figure (14) Bicycles routes network in Amsterdam

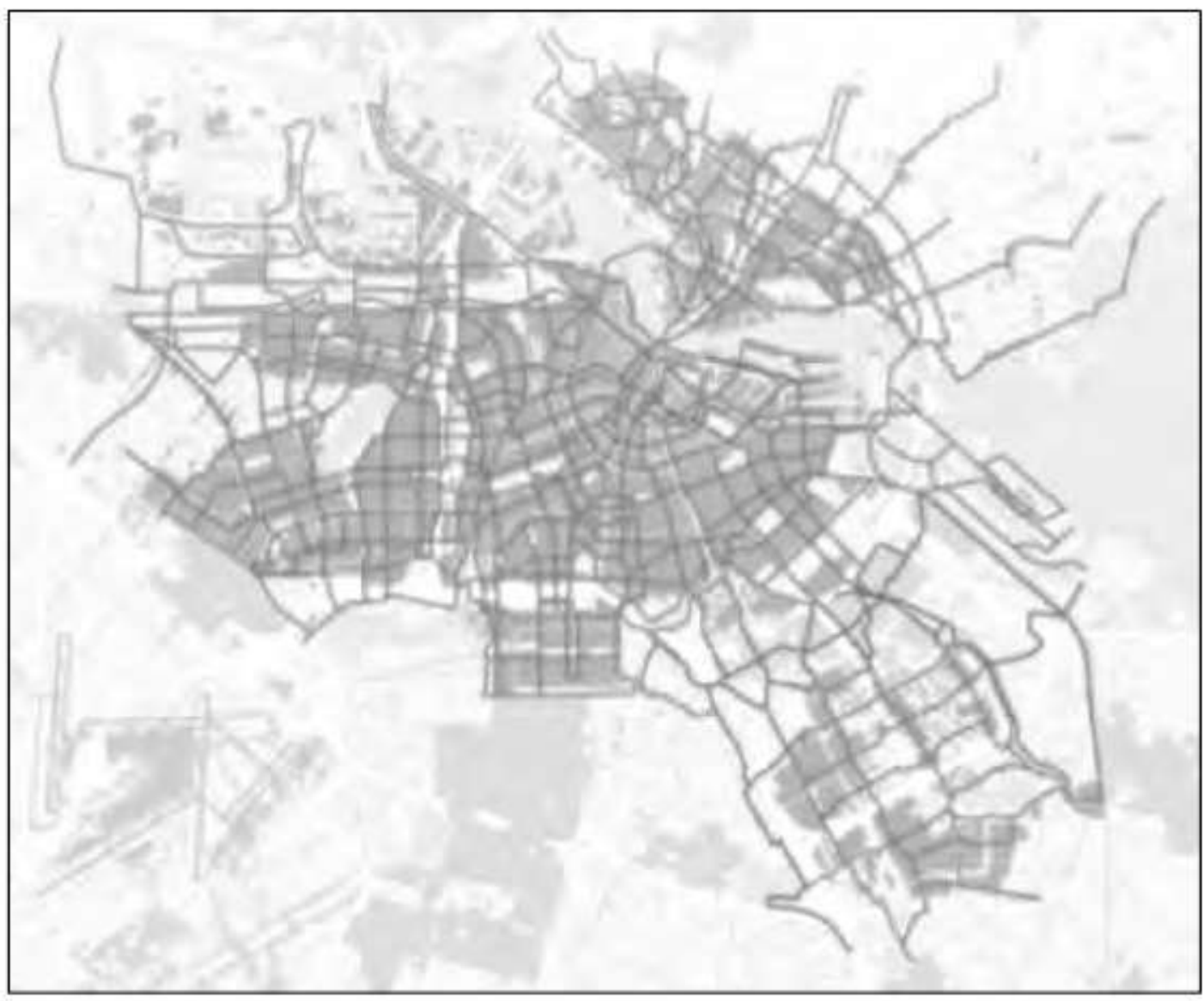

Figure (15) Photos of Amsterdam bicycles routes
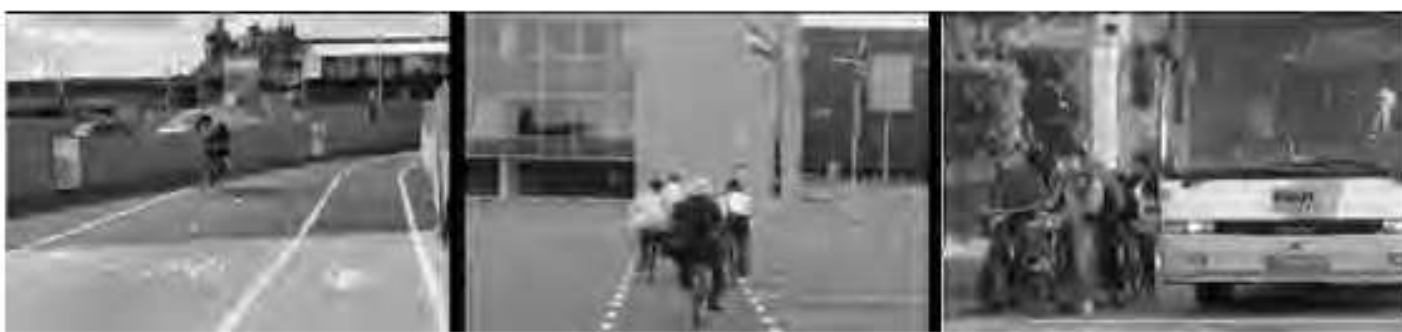
Figure (16) Photos of bicycle traffic signs in Amsterdam.

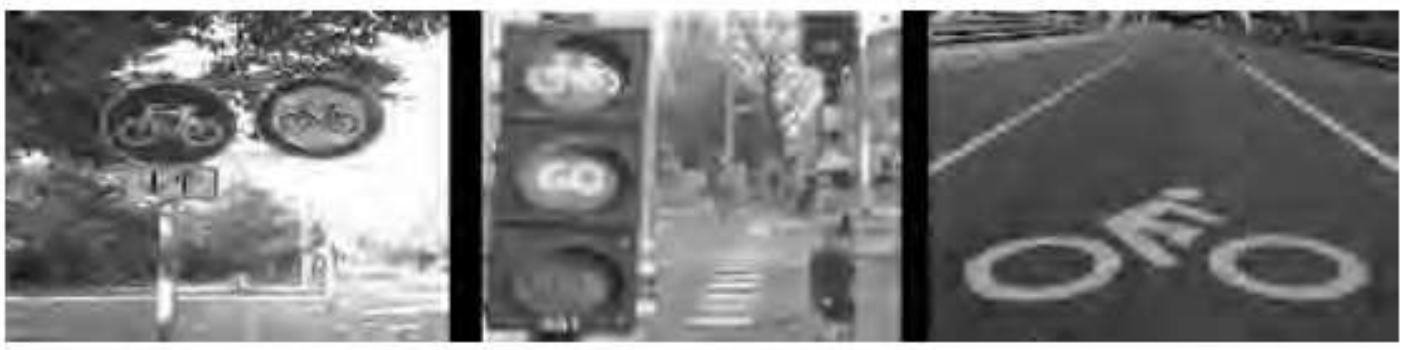

\section{APPENDIX 2: Facts about Shebin El-koum cycling network}

Figure (17) illustrates the proposed cycling network in Shebin El-koum city. Table ) identifies the type of cycling route in each street.

Figure (17) Proposed network of bicycles routes network

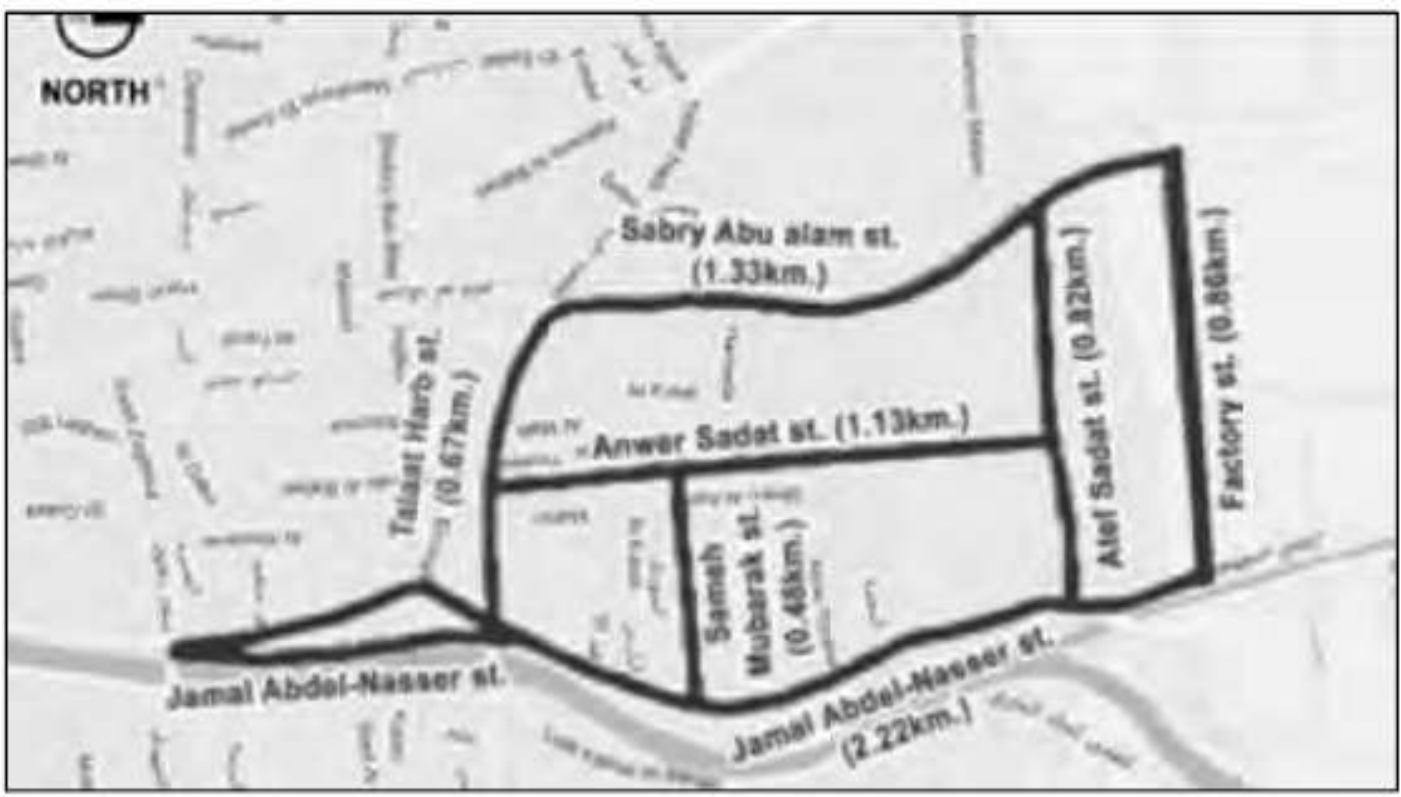

Table (3) Types of cycling routes in Shebin El-koum city

\begin{tabular}{lccc}
\hline$\#$ & street & $\begin{array}{c}\text { Length } \\
\text { (in } \mathbf{k m} .)\end{array}$ & $\begin{array}{c}\text { Exclusive bicycle lanes type } \\
\text { (according to street width) }\end{array}$ \\
\hline 1 & Jamal Abdel-Nasser & 2.22 & by separators and colored marking \\
\hline 2 & Anwer Sadat & 1.13 & by separators only \\
\hline 3 & Sabry Abu Alam & 1.33 & by separators and colored marking \\
\hline 4 & Talaat Harb & 0.67 & by separators and colored marking \\
\hline 5 & Sameeh Mubarak & 0.48 & by separators and colored marking \\
\hline 6 & Atef Sadat & 0.82 & by colored marking only \\
\hline 7 & Factory & 0.86 & by colored marking only \\
\hline
\end{tabular}




\section{Notes and References}

1 GRID-Arendal, United Nations Environment Program, Online Library, http://maps.grida.no/go/graphic/world-greenhouse-gas-emissions-by-sector2.

2 Chamon, M., Mauro, P., \& Okawa, Y., The implications of mass car ownership in the emerging market giants, Economic Policy, vol. 23, pp. 31, 2008.

3 International Energy Agency, Key World Energy Statistics, official report, Soregraph publisher, pp.33, 2010.

4 Gardner, G., Power to Pedals, World Watch Magazine, Volume 23, No. 4, Worldwatch Institute, pp.1, 2010.

5 United States Environmental Protection Agency (EPA), Emission facts-Greenhouse Gas Emissions from a Typical Passenger Vehicle, pp.2, 2005.

6 Davis, T and Hale, M., Public Transportation's Contribution to U.S. Greenhouse Gas Reduction, Technical report, Science Applications International Corporation, 2007.

7 Amin, N., Reducing Emissions from Private Cars: Incentive measures for behavioural change, Technical report, United Nations Environmental Programme, 2009.

B The International Association of Public Transport, Public transport alleviates congestion, online article, www.uitp.org/advocacy/pdf/alleviates_congestion.pdf, last accessed feb. 2012.

9 Bowman-Melton Associates, Inc., Bicycle Commuter's Handbook, part2, online report, http://www.nctcog.org.

10 Engbers, L. \& Hendriksen, I., Characteristics of a population of commuter cyclists in the Netherlands: perceived barriers and facilitators in the personal, social and physical environment, International Journal of Behavioral Nutrition and Physical Activity, pp. 3, 2010.

${ }^{11}$ Van Dyck, D., De Bourdeaudhuij, I., Cardon, G. and Deforche, B., Criterion distances and correlates of active transportation to school in Belgian older adolescents, International Journal of Behavioral Nutrition and Physical Activity, pp. 5, 2010.

12 American Association of State Highway and state officials-AASHTO, Guide for the development of bicycles facilities, official report, pp.7-9, 1999.

${ }^{13}$ Association of Australian and New Zealand road transport and traffic authorities, On-road Arterial Bicycle Routes, Cycle Notes, No.7, pp.3-4, 2000.

14 Garber, N.J. \& Hoel, L.A. Traffic \& Highway Engineering, 4th Edition, Cengage Learning Publisher, 2008.

15 Forni, J.F., Colquhoun, Th. \& Hasen, D., The use of coloured surfacing in road layout, European Transport Conference, pp.377-386, 1997.

${ }^{16}$ Traffic and Access standards section-department of Transport, Energy and InfrastructureGovernment of South Australia, Distinctive Coloured Pavement Bicycle Lanes, Operational Instruction Report, official report, pp.4-5, 2009.

17 Turner, Sh., Sandt, L., Toole, J., Benz, B. \& Patten, R., FHWA University course on bicycle and pedestrian transportation: student workbook, pp.244-245, 2006. 
18 The State of Hawaii-Department of Transportation, Bike master plan report, official report, 2003.

19 Jensen, S., Rosenkilde, C. \& Jensen, N., Road Safety and perceived risk of cycle facilities in Copenhagen, official report for City of Copenhagen authority, pp.8, 2007.

${ }^{20}$ Tilahun, N.Y., Trails, Lanes, or Traffic: valuing bicycle facilities with an adaptive stated preference survey, Master Thesis, The University of Minnesota, USA, pp.19, 2005.

${ }^{21}$ Watertown bicycle and pedestrian committee, Bicycle Parking Plan for Watertown, official report, pp.1-2, 2007.

22 Greater Manchester Local Transport Plan Cycling Group, Greater Manchester cycle parking guidelines, official report, pp. 2, 2002.

23 ACT Planning and Land Authority, Bicycle Parking Guidelines, official report, pp.8-9, 2006.

${ }^{24}$ Watertown Bicycle and Pedestrian Committee, Bicycle Parking Plan for Watertown, official report, pp.5-6, 2007.

25 ACT planning and land authority, Bicycle Parking guidelines, Official Report, Australia, pp.26-38, 2006.

${ }^{26}$ The Sustainable Transport Charity, Cycle parking, Information sheet FF37, http://www.sustrans.org.uk.

27 The City of Minneapolis Bicycle Program, Bicycle Facility Design Guidelines, official report, pp.148-171, 2010.

28. Arlington County Commuter Services Agency, Bicycle Parking Standards and Classifications, http://www.commuterpage.com.

${ }^{29}$ Department of Transport - UK., Cycle Parking Key Principle Design Guidance, official report, pp.11, 2009.

30 Statistics Netherlands Agency, Official website, http://statline.cbs.nl, last accessed Dec. 2010.

${ }^{31}$ Ibid., The Kentucky Institute for the Environment and Sustainable Development, 2010.

32 White, L.K., Bicycle Lifecycle: Amsterdam's Two-Wheeled Culture, online article, userwww.sfsu.edu/ Ikwhite/docs/amsterdambikeculture.pdf, last accessed, Feb. 2012.

${ }^{33}$ Buehler, R. and Pucher, J., At the Frontiers of Cycling: Policy Innovations in the Netherlands, Denmark, and German, Journal of World Transport Policy and Practice, Vol.13, No. 3, 2007.

${ }^{34}$ Ibid., The Kentucky Institute for the Environment and Sustainable Development, 2010.

${ }^{35}$ Ibid., The Kentucky Institute for the Environment and Sustainable Development, 2010.

${ }^{36}$ Ibid., Ministry of transport - Netherlands, 2009.

37 Langenberg, P., Cycling in Amsterdam; Developments and policies, online article, www.velomondial.net/velomondiall2000/PDF/LANGENBE.PDF, last accessed Feb. 2012.

38 Ibid., Buehler, R. and Pucher, 2007.

39 The Kentucky Institute for the Environment and Sustainable Development, Sustainable Communities, Journal of environmental and sustainability, issue 21, pp.39, 2010.

40 Ibid., Ministry of transport - Netherlands 2009. 
${ }^{41}$ Ibid., The Kentucky Institute for the Environment and Sustainable Development, 2010.

42 Buehler, R. and Pucher, J., Making Cycling Irresistible: Lessons from The Netherlands, Denmark and Germany, Transport Reviews, Vol. 28, No. 4, 495-528, 2008.

${ }^{43}$ Richelsen, A. and Søhuus, P.M. (eds), Catalogue of best practice; Urban SustainabilityLearning from the best, European Green Capital Award. 2010/2011.

${ }^{44}$ Watson, J., European Green City Index; Assessing the environmental impact of Europe's major cities, Siemens AG publisher, Germany, 2009.

${ }^{45}$ Statistics Netherlands official website, Last accessed Feb. 2012.

46 Peach, J., Sustainable Communities and Amsterdam's Bicycle Network, This big city blog, http://thisbigcity.net/developing-sustainable-communities-amsterdams-bicyclenetwork/, last accessed Feb. 2012.

${ }^{47}$ Ibid., The Kentucky Institute for the Environment and Sustainable Development, 2010.

${ }^{48}$ The Kentucky Institute for the Environment and Sustainable Development, Sustainable Communities, Journal of environmental and sustainability issues, issue 21, pp.36, 2010.

49 The Infrastructure, Traffic and Transport Office - the City of Amsterdam, Amsterdam paves the way for cyclists, www.fiets.amsterdam.nl, online brochure, Last access Feb. 2012.

${ }^{50}$ Ibid., The Infrastructure, Traffic and Transport Office - the City of Amsterdam, 2012.

51 Ministry of transport - Netherlands, Cycling in the Netherlands, official report, pp.27, 2009.

52 Ibid., Ministry of transport - Netherlands, 2009.

${ }^{53}$ Ibid., The Infrastructure, Traffic and Transport Office - the City of Amsterdam, 2012.

54 Berrini, M. and Bono, L., MEASURING URBAN SUSTAINABILITY-Analysis of the European Green Capital Award 2010 \& 2011 application round, 2010.

${ }^{55}$ Physical Planning Department - city of Amsterdam, Amsterdam Pocket Atlas, official document, 2006. 